\title{
The process of closing dynamics applied to the ventilation network of Paroșeni mine
}

\author{
Florin Rădoi * , Doru Cioclea, Corneliu Boantă, and Cristian Tomescu \\ National Institute for Research and Development in Mine Safety and Protection to Explosion - \\ INSEMEX , 32-34, G-ral Vasile Milea Street, Petroșani, Romania
}

\begin{abstract}
The decision to begin the process of closing/preserving a mining objective requires the analysis of a complex of factors that interact and influence the efficiency of decision. Solving the ventilation networks with the help of computing is a huge step forward that allows optimization of the air management and real-time visualization of network changes. The method of solving the ventilation network with the help of the computation, allows the modeling and solving of the ventilation networks as well as any simulations of changes that may occur in the ventilation system regardless of its complexity, during the closing period. This paper will present the process of closing dynamics in a complex ventilation network.
\end{abstract}

\section{Introduction}

The decision to close a mine [1] requires the analysis of multiple factors that influence its effectiveness and that can be grouped as follows:

- The class of economic factors, including those elements on the basis of which the closure of a mine leads to improvement of the trader's economic situation, either by increasing the labour productivity of remaining objectives or by reducing the recorded losses;

- The class of natural and constructive factors, referring to the degree of mineral reserve provision, opened and prepared reserves, lengths of transportation, hydrogeological conditions, geological structure, seismic protection, floods;

- The class of social-political factors, which includes:

- unemployment rate in the area;

- standard of living and comfort;

- alternatives in terms of employment;

- degree of industrial development;

- possibilities of financial support offered by the state for potential redundant persons who can't find a job.

\section{Technical aspects regarding mine closure}

\footnotetext{
* Corresponding author: florin.radoi@insemex.ro
} 
The technical documentation will include the following elements:

- technical-economic memorandum regarding the situation of the mine to be closed;

- phased closure schedule for underground mining works (coal faces, preparatory works, openings, etc.);

- schedule for closing access ways to surface (adits, runs, upraises, wells, drillings with a diameter larger than $200 \mathrm{~mm}$, etc.);

- the phased project for ventilation;

- the program for decommissioning technical equipment to be recovered and power supply points (stations and power distribution points) in conjunction with the mine closure program;

- phased program for the capitalization or demolition of surface constructions and ecological restoration of affected lands (dumps, ponds, excavation pitches, water courses, sinking areas, areas damaged by deposits of materials, wastes, building elements);

- prevention and protection plan phased on closing steps;

- general and detailed topographical plans of underground mining activities, completed to date;

- topographical plan of the area, including sinking areas, completed to date.

The general and partial ventilation will be performed in correlation with the mine closure stages based on the annual ventilation project (developed according to the RSSM), [2], quarterly reviewed depending on the changes arose in the circuits following the closure stages. The ventilation project will be approved by the technical management of the coordinating institution and will be supported by the technical management of the branch.

\section{Solutions regarding closure of underground and mine workings connected with the surface}

The closure of the underground mining works (coal faces, first mining and development workings, etc.) [3] will be carried out in a phased manner, backing from the mine field boundary towards the ventilation circuits, found under the general depression of the mine, inclusively towards the surface connection paths, based on a technical closure project that will include:

- the state of mine workings in terms of support, free profile, set-up and traffic and transportation possibilities. Where needed, the mine workings to be re-engineered or those needing the transportation path for the evacuation of recovered technical equipment to be rebuilt shall be specified;

- schedule for the closure of underground mine workings by horizons (elevation marks) and within each horizon;

- access ways (circulation and transport) for each closure stage, indicating routes for evacuation of recoverable machinery;

- mine workings closure technology (backfilling, directed caving in or abandonment as they are). Mechanical installations (devices) used to recover support;

- types of mine closure dams, along with their site location on topographic plans. In areas with possible floods, the dams will be sized to withstand the foreseeable water pressure;

- the flow of accumulated water and the forecast of mine workings flooding over time. The risk of water accumulation for neighbouring mines or an unabandoned part of the mine and measures to prevent their flooding;

- risk perimeter for surface caving-ins and time tracking of the caving area. 
The closure of mine workings connected with the surface (adits, runs, upraises, wells, drillings with a diameter larger than $200 \mathrm{~mm}$, etc.) will be carried out based on a technical project that will include:

- Closure of mine workings with a less than $30^{\circ}$ dip (adits, runs):

o Approach of mine workings closure:

- by backfilling for mine workings that have as ceiling, all the way up to the surface, a package of rocks, not thicker than $50 \mathrm{~m}$;

- by taking of the metal props or leaving the working as it stands, if the working is caved in stable rocks and if the stability of surface terrain is certified by geotechnical studies; in this situation measures will be taken to avoid the entry of foreign persons into the underground through excavations behind the dams;

- backfilling will be performed with the use of flight conveyers, conveyor belts, front dump cars or by hydraulic transport of a consistent mixture of thermal ash and water, with binder additions, put into operation by means of a kneading -pumping aggregate, the pulp being directed to the place of deposition by pipes or hoses.

- Approach of mine entrance closure for mine workings connected with the surface

- with safety earth walls, for workings that were closed by backfilling;

- with concrete stoppings having a thickness of minimum $0.5 \mathrm{~m}$, embedded in compact rock throughout the entire perimeter, for workings that were closed by taking of the metal props or leaving the working as it stands.

o Setting up safety pipes within mine dams: "swan neck" type safety pipes will be installed within dams, for water evacuation.

- Closure of mine workings with a dip higher than $30^{\circ}$ (adits, raises):

o Approach of mine workings closure:

- by building a dam, resistant to the backfill pressure, embedded in the walls of the adit or raise, located at an accessible point, where the thickness of rocks in the mine working's ceiling, all the way up to the surface, measures at least $50 \mathrm{~m}$ vertically; - by backfilling the mine working between the dam and the adit or raise entrance;

- for dips lower than $60^{\circ}$, backfilling will be performed with the use of flight conveyers, conveyor belts, gutters or downstream pipelines or by hydraulic transport of a consistent mixture of thermal ash and water, with binder additions, put into operation by means of a kneading -pumping aggregate, the pulp being directed to the place of deposition through pipes or hoses.

o Approach of mine entrance closure for mine workings connected with the surface

- with at least $0.5 \mathrm{~m}$ thick safety earth walls embedded in compact rock over the entire mining area;

- or with a reinforced concrete plate, resistant to a pressure of $32 \mathrm{kN} / \mathrm{m}^{2}$;

o Setting-up gas control pipes and fireproof pipes within dams and fitting the concrete plate with window, for monitoring the level of backfill and the fireproof gas drainage pipe, if necessary. When closing ascendant mine workings, "swan neck" type safety pipes will be installed within dams and pipes, for water evacuation.

- Closure of vertical mine workings (circulation and ventilation shafts, air funnels and boreholes having a diameter larger than $200 \mathrm{~mm}$ ):

$\circ$ the required amount of backfill material depending on the pit volume and density of the material used;

o type of backfill material and its granulation, stating that:

- the maximum grogs size will not exceed $250 \mathrm{~mm}$;

- a material that has no tendency to form vaults, having a grain size of less than $100 \mathrm{~mm}$ (gravel, slag, sandstone, concrete or brick pieces) is used on the last section of $50 \mathrm{~m}$ to surface; 
- if the occurrence of air - methane mixtures is possible, wet and fine grain backfill material is required;

- in the case of water accumulation in the pit, it is necessary to use backfill with a specific gravity of more than $1.3 \mathrm{~kg} / \mathrm{dm}^{3}$;

o forecast of the water flow that accumulates in the pit and from where it flows;

o methane emission regime and areas where it may occur (abandoned mine workings, coal tar interceptions and tectonic disturbances);

o the necessary preparatory work to be carried out before the pit's backfilling:

- construction of dams in the workings connected with the surface with the pit or boxhole raises, which are to be backfilled, dimensioned at the pressure created by the backfilling material, in order to prevent the leakage of the material through these workings;

- if it possible as safety is concerned, removal of set-ups in the pit, obstructing the section and preventing free fall of the backfill;

- setting-up of the pit entrance in order to avoid putting in oversized backfill material;

- assembling the means of continuous transportation of backfill material towards the point of discharge into the pit;

- fencing the surface restricted area, within $20 \mathrm{~m}$ radius around the well, until the end of the backfilling activity, to prohibit the access of the unauthorized persons; in this respect, warning signs stating prohibited access will also be displayed;

o organizing the backfilling activities with reference to:

- periodic tracking of filling level and material used as backfill, in accordance with the project;

- tracking the shrinkage of the backfill column and filling it up after completion of the backfilling activities;

- the method chosen for filling up the voids under the reinforced concrete plate, resulted after shrinkage, with backfill material. When applying the technology, account shall be taken of the relatively small size of the manway and that by gravitational disposition complete filling of voids is not possible;

$\circ$ the means for sealing surface connections with the pit (ventilation ways, ducts and cable ways, pipes, etc.);

o means of pit closure module by using a reinforced concrete plate resistant to a pressure of $32 \mathrm{kN} / \mathrm{m}^{2}$. Possibilities of using the support from the pit entrance as a prop surface for the closure plate;

o means of fitting the closure plate with an observation window, for monitoring backfill column levels and the gas drainage pipe, when necessary;

o means of surface marking the center of the well entrance, in case the closure decision provides for the reinforced concrete plate to be covered with a layer of soil. The mark shall bear the name, the axis coordinates and the diameter of the well;

o the graphic part (pit section and its set-up, pit height profile, major tectonic strains and disruptions intercepted when digging the pit, shop drawing for the closure plate.

Pit filling operations shall be carried out without intermittences, with no breaks allowed.

As far as possible, when performing pit's backfilling the intercepted groundwater shall be taken into account and shall be recovered by a bed of clay of at least $20 \mathrm{~m}$ vertically.

The entrance of the pit backfilled with unconsolidated rock must be covered with a reinforced concrete plate. The concrete plate must be provided with an access window to monitor and apply any refill measures.

Surface access works (slopes and galleries) should be closed shortly after the closure decision has been taken, for reasons of population's safety. Choosing the right closure or remediation technology depends on the following factors:

- location of the gallery in relation to the surface, 
- geological and hydrogeological conditions,

- gallery function,

- general state of the gallery in terms of stability and accessibility.

In order to achieve a correct closure of abandoned galleries, the following constructive solutions compatible with best practices can be adopted:

- construction of a dam at the gallery's entrance out of precast concrete or concrete;

- backfilling a minimum $10 \mathrm{~m}$ long section, immediately behind the gallery opening (the total length of the backfilled area varies depends on surface stability on the gallery alignment);

- full gallery backfilling;

- closure of the gallery entrance by detonation for caved-in galleries in order to restore the natural environment.

- closing a gallery entrance with a lockable iron gate is only permitted until the closure activities begin.

Mine flooding is an integral part of the mine closure and rehabilitation process. After completion of the preparatory activities (backfilling, stabilization, removal of contaminated machinery, recovery of recyclable metals, etc.), mine water discharge will be reduced and finally stopped. At this stage, the natural intake of underground water will lead to mine filling (uncontrolled flooding).

Flood concepts and strategies need to be adapted to site specificity, but without omitting well-established routine procedures. It is necessary to continually update the concept underlying the flood and adapt it to the results of the monitoring that is being carried out concurrently (flood monitoring).

All these solutions for the closure of underground and mine workings connected with the surface were applied both to the restriction and to the closure of the Paroseni mine.

\section{The ventilation network of the Paroșeni mine during the closure period}

In order to determine the dynamics of the changes of the ventilation network, $[4,5,6,7]$, in relation to the initial stage, it is necessary to consider the mining works that will be phased out of operation, respectively of the sub-circuits that will come into operation, in perspective, in relation with maintaining the production capacities. All mining works that constitute sub-circuits or parts of sub-circuits, which are eliminated or introduced into the ventilation network, modifying its architecture are a closing step. In order to determine the succession of the closing stages, [8] it will be taken into account the safety ensuring conditions in the underground by properly dimensioning the air flows, respectively by judicious use of the ventilations constructions.

The results of the closing stage no. 1 showed reduced changes, less than $12,5 \%$, compared to the results obtained on the basic ventilation network. At the mine level, the air flow decreased by $3.04 \%$, from $94.13 \mathrm{~m}^{3} / \mathrm{s}$ to $91.27 \mathrm{~m}^{3} / \mathrm{s}$. At the level of the main ventilation station no. 18 VOD 3.0, the annual cost of ventilation decreased by $1.83 \%$.

The results of the closing stage no. 2 showed very big changes, more than $100 \%$, compared to the results obtained on the basic ventilation network. At the mine level, the air flow decreased by $48.56 \%$, from $94.13 \mathrm{~m}^{3} / \mathrm{s}$ to $48.42 \mathrm{~m}^{3} / \mathrm{s}$. At the level of the main ventilation station VOKD 2.4, the annual cost of ventilation decreased by $55.53 \%$.

The results of the closing stage no. 3 showed moderate changes, less than $43 \%$, compared to the results obtained on the basic ventilation network. At the mine level, the air flow decreased by $3.45 \%$, from $94.13 \mathrm{~m}^{3} / \mathrm{s}$ to $90.88 \mathrm{~m}^{3} / \mathrm{s}$. At the level of the main ventilation station no. 18 VOD 3.0, the annual cost of ventilation decreased by $0.27 \%$. 

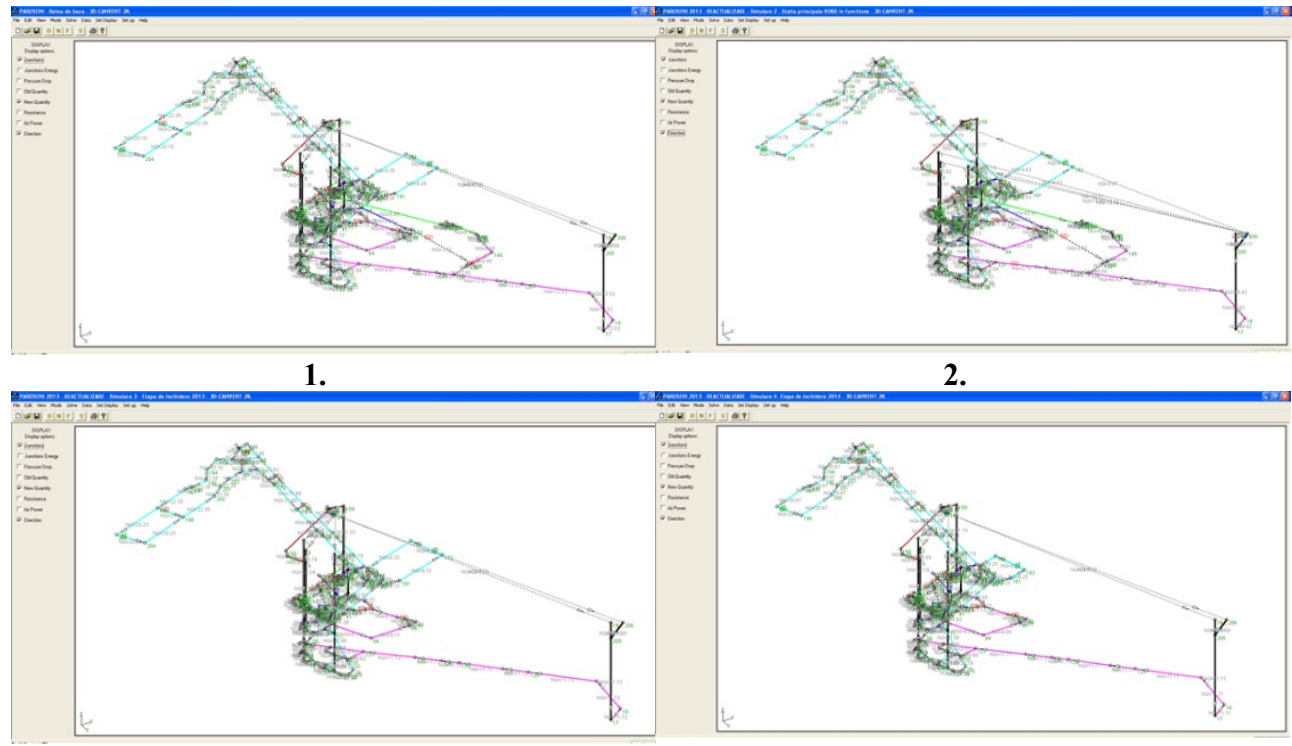

3.

4.

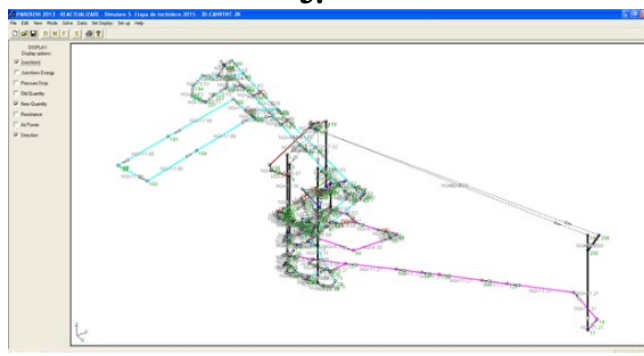

5.

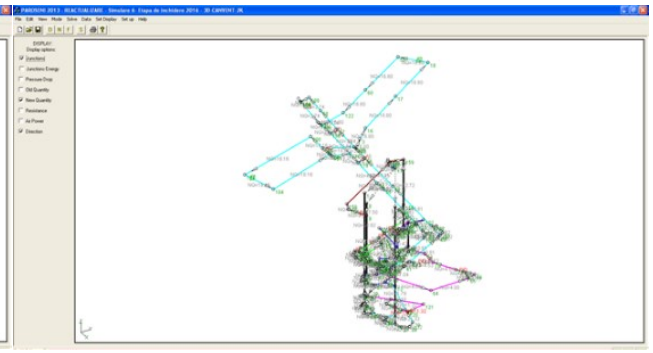

6.

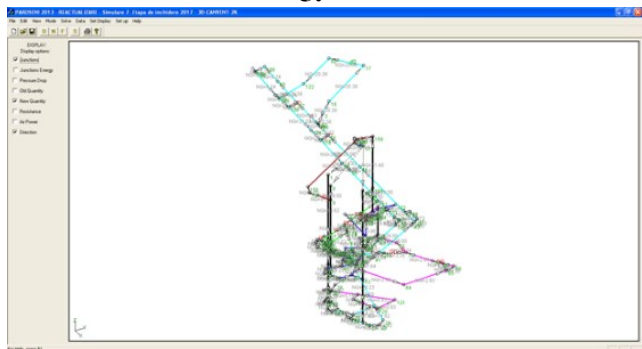

7.

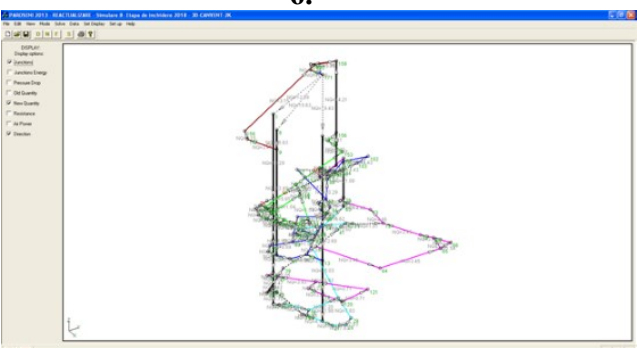

8.

Fig. 1. Ventilation network of Paroșeni mine for the 8 closing stages (as numbered in each figure)

The results of the closing stage no. 4 showed moderate changes, less than $43.5 \%$, compared to the results obtained on the basic ventilation network. At the mine level, the air flow decreased by $3.45 \%$, from $94.13 \mathrm{~m}^{3} / \mathrm{s}$ to $90.73 \mathrm{~m}^{3} / \mathrm{s}$. At the level of the main ventilation station no. 18 VOD 3.0, the annual cost of ventilation decreased by $0.37 \%$.

The results of the closing stage no. 5 showed moderate changes, less than $45 \%$, compared to the results obtained on the basic ventilation network. At the mine level, the air flow decreased by $7.55 \%$, from $94.13 \mathrm{~m}^{3} / \mathrm{s}$ to $87.02 \mathrm{~m}^{3} / \mathrm{s}$. At the level of the main ventilation station no. 18 VOD 3.0, the annual cost of ventilation decreased by $1.37 \%$.

The results of the closing stage no. 6 showed moderate changes, less than $40 \%$, compared to the results obtained on the basic ventilation network. At the mine level, the air 
flow decreased by $7.39 \%$, from $94.13 \mathrm{~m}^{3} / \mathrm{s}$ to $87.17 \mathrm{~m}^{3} / \mathrm{s}$. At the level of the main ventilation station no. 18 VOD 3.0, the annual cost of ventilation decreased by $1.23 \%$.

The results of the closing stage no. 7 showed significant changes, less than $61 \%$, compared to the results obtained on the basic ventilation network. At the mine level, the air flow decreased by $38.43 \%$, from $94.13 \mathrm{~m}^{3} / \mathrm{s}$ to $57.95 \mathrm{~m}^{3} / \mathrm{s}$. At the level of the main ventilation station no. 18 VOD 3.0, the annual cost of ventilation decreased by $36.25 \%$.

The results of the closing stage no. 8 showed very big changes, more than $100 \%$, compared to the results obtained on the basic ventilation network. At the mine level, the air flow decreased by $49.68 \%$, from $94.13 \mathrm{~m}^{3} / \mathrm{s}$ to $47.36 \mathrm{~m}^{3} / \mathrm{s}$. At the level of the main ventilation station no. 18 VOD 3.0, the annual cost of ventilation decreased by $89.27 \%$.

\section{Conclusions}

- The decision on closing a mining objective mainly takes into account economic, natural and social political factors;

- The technical documentation for closing a mining objective comprises a series of elements, one of the most important being the ventilation project on closing stages;

- Mainly, the closure of mine workings, especially the underground ones, is carried out phased, in withdrawal, from the limit of the extraction field to the main ventilation circuits and finally to the connection routes with the surface;

- The Paroșeni mine ventilation network is a diagonal complex and requires special attention during its restriction;

- During the closure of the Paroseni mine's ventilation network, it was necessary to consider, analyze and apply 8 distinct stages, which were applied to solve the ventilation network, to optimize it and to establish the optimal distribution of the air flows, respectively the operating regime of the of the main active fan.

\section{References}

1. Mine law no. $85 / 2003$.

2. Solschi A. G., Technical program of Paroşeni mine closure, (2011).

3. F. Rădoi, Closing solutions applied to Mines in Jiu Valley, ANNALS OF THE UNIVERSITY OF PETROŞANI - MINING ENGINEERING vol. 17, Universitas Publishing House, Petroşani-România, ISSN 1454-9174, (2017)

4. D. Cioclea, I. Gherghe, C. Boantă, F. Rădoi, N. Ianc, A. Matei, R. Laszlo, Update, optimization of the Paroșeni mine with the 3D CANVENT program, (in Romanian) INSEMEX study (2013).

5. F. Rădoi, C. Lupu, D. Cioclea, I. Gherghe, C. Tomescu, E. Chiuzan, V. M. Păsculescu, Updating the ventilation network of Petrila Mining unit subject to closure, The sixth BALKAN MINING CONGRESS, Petroşani, România, ISBN 978-973-741-435-9 (2015).

6. F. Rădoi, C. Boantă, N. Ianc, A. Matei, M. Prodan, Comparative solving of a ventilation network and its validated results, 18th International Multidisciplinary Scientific Geoconference, SGEM 2018, Volume 18, Science and Technologies in Geology, Exploration and Mining, Issue: 1.3, 2-8 july, Albena, Bulgaria, Pages: 175-182, ISBN 978-619-7408-37-9, ISSN 13142704, DOI: $10.5593 /$ sgem2018/1.3 (2018).

7. 3D Canvent - Mining and Minerals Sciences Laboratories Underground Mine Environment and Ventilation, User manual - program 3D - Canvent $-2 \mathrm{~K}$.

8. F. Rădoi, Optimization of Jiu Valley mine ventilation, subject to closure, in order to increase work safety, Doctoral thesis, University of Petrosani, Domain of Doctorate, Mining, Oil and Gas, (2018). 